\title{
Does national culture affect the intensity of volatility linkages in international equity markets?
}

\author{
Stephanie Rothonis, Duy Tran, Eliza Wu* \\ University of Technology Sydney, UTS Business School, Ultimo NSW 2007, Australia
}

This Version: 20 May, 2015

${ }^{*}$ Corresponding author Email: eliza.wu@uts.edu.au. Tel. +61295143905. 


\begin{abstract}
We investigate whether cultural proximity can intensify volatility linkages across international equity markets. Using daily data on national stock market indices for a sample of 49 developed and developing countries, we find that our cultural distance measure is inversely related to the strength in return volatility linkages between country pairs. We also find evidence that national culture is particularly important when there is a wider common investor base between two markets with greater bilateral portfolio investments. Furthermore, we reveal that when one market within a country pair is relatively less open than another market in terms of their foreign exchange trading activity then the cultural distance between them will further weaken volatility linkages. Our results suggest that market participants with similar cultural backgrounds respond to and impound information into equity prices in a similar fashion and this works to intensify volatility linkages around the world.
\end{abstract}

Keywords: Cultural Distance, Volatility Linkages, Realized Volatility, GARCH 


\section{Introduction}

Culture refers to the values and norms of a particular society or country, which in turn influences and imposes informal constraints one's perceptions and behaviour. Therefore, the way in which investors behave in response to information can conceivably be influenced by their culture. Previous studies have examined the role of culture in different areas of finance. Importantly, it has been shown that culture is important in the development of financial systems (Kwok and Tadesse, 2006), the legal system, levels of investor protection and ultimately economic development (Stulz and Williamson, 2003).

It is established that culture not only systematically biases the actions of investors but also corporate managers and can thus influences stock price behavior. For instance, Roe (2003), Chan and Cheung (2012), Han et al. (2010) and Bae et al. (2012) find there is a clear role for national culture on corporate policies and the strength of firms corporate governance practices. Drogendijk and Slangen (2006) also show that culture can help explain a company's foreign direct investment decisions. Similarly, it has been shown by Chan et al. (2005) and Parker and Parker (2014) that institutional investors invest in markets that are culturally similar to their home market as they share a common language or are geographically proximate, consistent with a familiarity bias (Huberman, 2001). Aggarwal and Goodell (2010) identify in particular that certain cultural dimensions like uncertainty avoidance are responsible for firms inability to access external finance. Chui et al. (2010) find that culture drives momentum trading in equity markets. Studies such as these, document that national culture plays an influential role in finance. However, there remains a gap in our current understanding on the role of national culture in synchronizing international financial markets. We attempt to fill this void.

Our study relates most closely to the literature examining national culture as a deter-

minant of stock market co-movement. It is related to the recent work of Eun et al. (2012) showing that culture is an important factor in determining stock price synchronicity and ex- 
erts systematic biases into investor behavior as reflected in higher stock price synchronicity. Instead, we focus on examining whether cultural proximity is reflected in a higher intensity in volatility linkages. In support of this, Akhtar et al. (2011) have shown that volatility linkages are stronger (more correlated) amongst Islamic assets, suggesting that a shared culture is likely to play a significant role in information transmission and asset pricing. Corroborating with this, Parker and Parker (2014) also find high stock market co-movement in Asian stock markets. They do not directly examine the role of culture, however, given their findings we can conjecture that culture comes into play, as one would expect countries within the Asian region to display similar cultural traits. Furthermore, other studies within this area of research have used cultural distance and shared religion as measures of cultural similarity, ultimately enabling them to be identified as factors leading to stock market integration (Lucey and Zhang, 2010). However, the prior literature has not comprehensively examined the role of different cultural dimensions on volatility linkages, as previous studies have only looked at Hofstede's cultural dimensions when examining the effect of cultural distance on stock market correlations.

Additionally, we contribute to the literature addressing volatility linkages across international markets. Cifarelli and Paladino (2008) shows that the flow of information leads to volatility transmission between markets, and there is sufficient evidence of volatility spillovers across certain markets. However, there is a gap between the culture and volatility linkages literature. To date, culture has not been considered as an influential factor that intensifies volatility linkages between countries. We go a step further by suggesting that the way in which investors interpret information is influenced by their culture, therefore, investors from culturally similar countries would interpret information in similar ways. Hence, volatility will be transmitted from one market to the other given that information transmission across markets leads to volatility linkages between these markets. 
The aim of this study is to examine the role of national culture on the intensity of volatility linkages across international markets, with a specific focus on the equity markets. We investigate this relationship by considering a global sample of 49 countries over a period of eight years, from 2003 to 2010. Akin to previous studies, we use Hofstede (2011)'s six cultural dimensions power distance index, individualism, masculinity, uncertainty avoidance index, long-term orientation and indulgence vs. restraint as the fundamental dimensions of national culture but we aggregate them into a composite cultural distance measure to study the relationship between cultural proximity and volatility linkages. We find that cultural proximity strengthens the information sharing and common investor reactions across equity markets. The effects of culture are stronger in countries with greater bilateral investments and a greater difference in relative openness.

We base our empirical analysis on Hofstede's cultural dimensions as prior studies have shown these are important determinants of financial activity. Kogut and Singh (1988) and Lee et al. (2008) also used a cultural distance index based on Hofstede's cultural dimensions to show that culture plays a role in the decision of a how a company would invest and enter a foreign market. They find that the greater the cultural distance between two countries, the less likely it is that a firm would invest significantly without cooperation. Other studies also document an important role for individual cultural dimensions. Recently, Li et al. (2011) examine the relationship between national culture and corporate risk-taking by focusing on three dimensions of culture that have been developed by Schwartz and Hofstede - harmony, individualism and uncertainty avoidance. They show that harmony and uncertainty avoidance are negatively related to a firm's risk-taking, whilst individualism is positively associated even after accounting for other factors. Kwok and Tadesse (2006) show that the financial system adopted by a country is dependent on that countrys degree of risk tolerance, which they measure using Hofstede's uncertainty avoidance index. Power distance, individualism and uncertainty avoidance are examined in Aggarwal and Goodell (2010) to investigate the relationship between culture and other institutional factors with the choice of national 
financing. They find that countries that exhibit a higher degree of uncertainty avoidance are more likely to favour institutions over markets, given the risk associated with participating in the market. Chui et al. (2010) find a positively significant relationship between momentum profits and individualism. However, our study is the first attempt to comprehensively examine the association between a comprehensive array of cultural dimensions and commonalities in volatility across markets.

Existing literature suggests that investors tend to invest in countries that would be familiar to them and culturally similar to their home market. French and Poterba (1991) observe that U.S, Japanese and U.K investors do not diversify their portfolios to an extent that allows them to reap the benefits of international diversification. They mention that investors perceive that there is a greater risk in holding foreign equity because they know little about foreign markets, thus resulting in a high degree of home bias. Indeed studies have looked into what factors lead to home bias, and most recently there has been a focus on behavioural explanations. For example, Grinblatt and Keloharju (2001) use familiarity attributes, culture, language and geographical distance, to explain investor preferences in the market by focusing on Finnish firms. Similarly, Amadi (2004) investigates foreign diversification by looking at what drives investor behaviour. He finds that factors such as common language and distance significantly affect international diversification, although the former shows a stronger affect confirming a familiarity bias. Anderson et al. (2011) consider the influence of culture in international diversification by employing five of Hofstedes cultural dimensions. They find that all four dimensions influence home bias, however some dimensions uncertainty avoidance, masculinity and long-term orientation have a stronger effect than others, whilst controlling for other factors that are shown to influence home bias in previous studies. Likewise, Beugelsdijk and Frijns (2010) suggest that culture is related to an investors investment decisions since culture influences ones behaviour. In particular they find that the higher the degree of individualism, the more aggressive investors are, and the more likely they are to invest in foreign markets. Whist on the other hand, the higher the degree 
of uncertainty avoidance the less likely it is for investors to invest in foreign assets. They also show that the more culturally proximate two countries are, the more likely it is that an investor would invest in the proximate foreign market. Researchers have also investigated the role of culture with respect to foreign portfolio investment (FPI). Aggarwal and Goodell (2010) provide evidence of the effects of culture on foreign portfolio investment patterns as they find that Hofstedes cultural dimensions are related to investment allocation. They also show that cultural variables interact with the gravity models to determine FPI patterns, thereby suggesting that culture should be considered separately from gravity models.

In summary, these studies illustrate that there is a clear link between culture and finance as aspects of culture influence the financial decisions of market participants. The remainder of this paper is organized as follows. Section II will survey the relevant literature. Sections III and IV will detail our empirical approach. Sections V will discuss the key results before concluding in Section VI.

\section{Related Literature}

Our study contributes new evidence to two separate literature strands. We first review the related literature on volatility linkages and secondly on national culture and financial linkages.

\section{A. Volatility linkages across markets}

We also contribute to the study of volatility linkages across international markets. Previous literature has established that volatility linkages exist across different markets due to the flow of information. Harvey and Huang (1991) use inter- and intra-day data to show that at the time that macroeconomic information is released, volatility in the foreign currency futures 
market increases. Fleming et al. (1998) particularly examine the role of information spillovers across the stock, bond and money markets in the U.S, whereby they develop a stochastic volatility model to test the degree to which information flows from one market to the other. They state that information generates volatility linkages across markets, either by investors reacting to information simultaneously or by investors reacting to new information in one market, which then has a flow-on effect in other markets due to changes in hedging positions. The results of their analysis provides evidence of linkages across these three markets, however they do not specify whether it is a result of common information flow or information spillover. Fleischer (2003) investigates the relation between volatility and information, showing that once information becomes known to investors, they change their positions in one market. This in turn has a flow-on effect in other markets, ultimately leading to market co-movement thereby providing evidence of information transmission. Furthermore, Wongswan (2006)) use intra-day data to examine information transmission from developed markets to emerging markets. He focuses on the transmission of information from the U.S and Japan, to Korea and Thailand, and they define information as macroeconomic news announcements. Wongswan finds that announcements made in the developed markets spillover into the emerging equity markets which is reflected in the volatility and trading volume of the latter markets. Colla and Mele (2010) also provide evidence that information linkages affect investors trading strategies and that when information linkages between markets are weak, the correlation of volumes are considerably low. They also find that trades from geographically close markets are positively correlated, whilst trades from geographically distant countries are negatively associated. Jiang et al. (2012) find that news announcements affect the intensity of volatility spillovers. Over the years research into this area has only increased due to the increase of globalisation, which has led to international market integration. Laopodis (2002) finds that volatility linkages between bond markets have strengthened since 1990 and he suggests that a more unified approach to macroeconomic policy-making is necessary, as markets become integrated and transmission between markets increases. Morana and Beltratti (2008) show 
that economic and financial integration contributes to stock market co-movement, with the former having a much stronger effect.

Other papers also examine the intensity of volatility linkages across different asset markets. Wang (2009) specifically investigates implied volatility linkages across US equity, bond and money markets, finding that equity and money markets share a stronger linkage than the other asset pairs which are much weaker. Fleischer et al. (2011) examine the volatility linkages between the U.S, Canada and Mexico, which they find increased following the establishment of the North American Free Trade Agreement (NAFTA). Giannopoulos et al. (2010) examine price interdependencies of the U.S, U.K, Japan and German equity markets. From their study they conclude that the US market has negative volatility spillover effects on the other three markets. They also find significance when investigating price spillovers across all markets. Sakthivel et al. (2012) also investigate volatility spillovers across specific equity markets by employing a bivariate Generalised Autoregressive Conditional Heteroskedasticity GARCH model. They find a positive bidirectional spillover between the U.S and the Indian markets, meaning that a shock in either one of these markets increases the conditional variance of the other market. This result is accounted for by the economic linkages of these two markets given their trade relations. They also find a positive volatility spillover from Japan to India and a negative spillover from the U.K to India. Korkmaz et al. (2012) find that volatility spillovers between Columbia, Indonesia, Vietnam, Egypt, Turkey, and South Africa are relatively low, however correlations increased following the global financial crisis.

Furthermore, studies have examined factors that may influence the strength of linkages between markets. For example, Sabri (2002) examines the relationship between stock market linkages and a number of factors, such as the number of cross-listed companies across different markets and stock market liberalisation which both have a positive effect on the intensity of volatility linkages. In particular, the study shows that over a four year period, from 1994 to 1998, stock market linkages increased for 15 out of the 16 markets examined. We 
contribute to such literature as we propose that culturally proximate countries perceive information in similar ways, meaning that there is a common flow of information, thus leading to information transmission and volatility linkages between markets. Furthermore, we make a methodological contribution as we study correlations in realised volatility linkages to proxy the intensity of volatility linkages.

\section{B. Culture and financial market linkages}

Yet, the direct role of culture in information transmission has not received much attention. Previous studies have used geographical distance, shared religion and language as proxies for cultural similarity. Walti (2005) investigates the effect of particular factors on stock market synchronisation and finds that common language leads to greater stock market co-movement whilst information asymmetries, proxied by geographical distance, leads to lower stock market correlation. Similarly, Eckel et al. (2011) use geographical distance as a determinant of stock market correlation and Lucey and Zhang (2010) use shared religion and cultural distance to measure the effect of culture on market co-movement. Eun et al. (2012) focus on tightness and individualism as two dimensions of national culture that matter for stock price synchronicity as they represent the external constraints on human behaviour and internal attributes, respectively. They find that both of these dimensions influence the degree of synchronicity between equity markets as expected - tightness leads to greater stock market synchronicity, whilst individualism has the opposite effect. They define tightness as a measure of the strength of a countrys social norms and the society's tolerance for deviant behaviour and that individuals within a country that displays tightness behave in similar ways. Therefore, when cultures are tight there is not much diversity in individual behaviour, meaning that stock price co-movement would be higher. Conversely, countries that display a higher degree of individualism are more confident in their own abilities and is associated with lower stock price synchronicity. They also show that in countries that are more globally 
integrated and open to trade, domestic culture does not significantly influence stock price synchronicity due to the mitigating effects of exposure to other foreign cultures.

In addition, Akhtar et al. (2011) examine the intensity of volatility linkages between Islamic and conventional markets by using a stochastic volatility model and standard pairwise correlations and volatility measures to capture volatility linkages. They show that volatility linkages involving at least one Islamic asset are lower than volatility linkages between two conventional assets, and that these linkages are more intense in Islamic countries than in non-Islamic countries. Although they do not directly assess the effect of culture on volatility linkages, given their results, we can acknowledge that culture comes into play when investigating the intensity of volatility linkages between certain markets. To our best knowledge, this study is the first attempt to comprehensively examine the influence of national culture on volatility linkages across international equity markets.

\section{Measures of Volatility Linkages}

We adopt two alternative measures to capture the intensity of volatility linkages across equity markets correlations of realized volatility and GARCH CCC. We discuss them in turn.

\section{A. Realized Volatility Linkage}

We use realised volatility $(\mathrm{RV})$, calculated as the sum of the square of daily returns over a trading month, as our first measure of equity volatility. For our purpose of studying the relationship between culture distance and volatility linkage, we want our sample data to cover as many countries as possible, hence, we choose to use daily prices instead of the intraday ones to compute the monthly RV. Andersen et al. (2001) show that realised volatility is an accurate measure of true volatility compared to other estimated measures 
based on parametric models such as the popular GARCH model. For another example, Koopman et al. (2005) show that realised volatility provides far more accurate volatility forecasts of the S\&P 100 compared to the forecasting power of the stochastic volatility and GARCH models. Similarly, Martens and Zein (2004) demonstrate the strength of realised volatility over implied volatility, as it provides much more accurate forecasts when applied to equity, foreign exchange and commodity markets. Others have also used this method as one of its advantages is that it is model-free.

To measure the volatility linkage between two countries, we compute the correlation coefficient of two countries' realised volatilities over time. For the sample of 49 countries, there will be 1176 correlation coefficients.

\section{B. GARCH Volatility Linkage}

The second methodology that we use to assess the intensity of volatility linkage is the multivariate Constant Conditional Correlation (CCC) GARCH model introduced by Bollerslev (1986). Many modifications have been made to the ARCH model that Engle (1982) had

introduced to suit the needs of financial research (see Bauwens et al. (2006)) for a survey of the different GARCH models).

Data on Hofstede's cultural dimensions are only reported at one point in time so to study their relationship with volatility linkage we rely on their variation across countries. We are implicitly assuming that culture changes very slowly over time and is practically time invariant. Hence, we use the CCC GARCH model to capture volatility linkages. 


\section{Empirical modeling}

\section{A. A generalised measure of cultural distance and its impact on volatility linkages}

As there remains mixed evidence on which cultural dimensions are important in driving investors decisions we compute a comprehensive cultural distance measure following the weighted approach of Yeganeh (2011). Essentially, we compute a generalised cultural distance index to study its relation with volatility linkages. The greater the cultural distance between two countries the less culturally proximate they are.

Consistent with Yeganeh (2011), our generalized cultural distance variable is based on the set of Hofstede's (2011) cultural dimensions available from Hofstede's website (http://www.geerthofstede.nl/dimension-data-matrix). However, we modify the cultural distance measure to include the two new cultural dimensions (long-term orientation (LTO) and indulgence versus restraint (IVR)) that were recently added to the original four cultural dimensions studied in earlier studies (power distance index (PDI), individualism (IDV), masculinity (MAS), and uncertainty avoidance (UAI)). Our modified cultural distance measure is computed as:

$$
C D_{i j}^{g e n}=\sum_{d=1}^{6} \pm w_{d} \frac{\left(H_{i, d}-H_{j, d}\right)^{2}}{V_{d}}=\sum_{d=1}^{6} \pm w_{d} C D_{i j, d}
$$

We adopt the modified composite cultural distance index proposed by Yeganeh (2011) as an improvement over Kogut and Singh (1988)'s measure as they highlight that the index should possess three important characteristics: 
1. Cultural asymmetry. The cultural distance between two countries should be shown by an algebraic positive or negative sign indicating the asymmetrical nature of cultural differences.

2. Dimensions alignment. In calculating the cultural distance, it is not legitimate to aggregate opposing cultural dimensions.

3. Weight of cultural dimensions. Since cultural dimensions have unequal implications, their relative weights should be factored in the calculation of cultural distance.

Yeganeh (2011) uses four original culture dimensions, the square root function, and the standard deviation of dimensions to compute the composite index. We modify their measure to account for all six dimensions, the square function combined with the variance of dimensions. Consistent with Yageneh (2011), first, we assign each dimension with a specific direction, either positive or negative. Cultural asymmetry and dimensions alignment are complementary to each other in the sense that cultural distances that are aligned will have the same sign, and the others will have the opposite sign. If differences of cultural dimensions are not aligned and added to each other, they will offset each other and falsify the measure of cultural distance. The appointed plus or minus signs are consistent with the alignment property of cultural dimensions. Second, instead of assuming equal weights, for each of the six cultural dimensions, different weights, wd, are used for individual cultural distances. This is in order to take into account the plausible dissimilarity and hence varying importance in cultural dimensions or societal actualities.

We follow Yeganeh (2011) to reveal the importance of each cultural dimension using regression based analysis represented by the following: 


$$
\begin{aligned}
g d p p a_{i} & =\text { const }+\sum_{d=1}^{6} \beta_{d} H_{i, d}+e_{i} \\
& =\text { const }+\beta_{1} P D I_{i}+\beta_{2} I D V_{i}+\beta_{3} M A S_{i}+\beta_{4} U A I_{i}+\beta_{5} L T O_{i}+\beta_{6} I V R_{i}+e_{i} .
\end{aligned}
$$

The weights $w_{d}$ used in equation 1 are hence:

$$
w_{d}=\frac{\left|\beta_{d}\right|}{\sum_{d=1}^{6}\left|\beta_{d}\right|}
$$

Using the data for our global sample of 49 countries listed in table I, we run regression 2 and obtain the coefficient estimates of 304.2 (for PDI); 90.6 (for IDV); 132.8 (for MAS); 9.7 (for UAI); 271.3 (for LTO), and 200.7 (for IVR) with the respective Newey-West t-statistics of $2.46 ; 0.91 ; 1.50 ; 0.139 ; 3.17$, and 1.81 respectively. The regression adjusted $R^{2}$ is $44: 33$. The results imply that dimensions PDI and LTO are significant at $5 \%$ and IV R at $10 \%$ level, whereas the other dimensions are statistically insignificant. We then use the estimates of each cultural dimension to calculate their respective weights, $w_{d}$, as $0.2464,0.0912,0.1499$, 0.0139, 0.3172, and 0.1812, indicating that PDI and LTO contribute the most weight in the composite index, and IDV and UAI the least.

Noting that the coefficients for dimensions PDI; MAS, and UAI are negative and those for the remaining dimensions are positive. We can use regression analysis to compute the weights and to determine the alignment properties as it is reasonable to consider each cultural distance measure as a mathematical vector with two standard components: a magnitude and a direction. The magnitude corresponds to the culture distance, $C D_{i j, d}$, of a particular pair of countries and the vector direction is determined by the alignment property of that culture dimension. By orthogonally projecting gross domestic product per capita (GDP) onto the linear subspace spanned by the columns of six cultural dimensions, we place all six culture distance vectors on a straight line, hence the sum operator with the signs is unambiguous. 
Having constructed the generalised cultural distance, $C D^{g e n}$, we examine its effect on financial volatility linkages by running the following regression:

$$
\text { VolatilityLinkage }_{i j}=\text { const }+\alpha C D_{i j}^{\text {gen }}+\sum_{k=1}^{9} \gamma_{k} \text { ControlledVariable }_{i j, k}+e_{i j}
$$

There are potentially many possible variables that could drive volatility linkages butt we are guided in our selection of control variables by the current literature (see Appendix Table VI). Specifically, econrisk, finarisk, and polirisk are the differences in International Country Risk Guide (ICRG)s economic, financial, and political risk indexes between two countries, respectively. Bekaert et al. (2011) show these indicators are relevant for stock market integration. Variable fxregm is a dummy variable equal to 1 if the two countries share the same forex regime, and zero otherwise. The inclusion of this variable is motivated by Kim et al. (2005) finding that the adoption of the euro as a common currency was an important determinant of enhanced stock market return linkages and financial integration across European countries. Variable region is a dummy variable equal to 1 if the two countries are in the same region, and zero otherwise. Beugelsdijk and Frijns (2010) find that equity investors tend to invest more in foreign markets within their own regions. Variable rating is the difference of the average sovereign credit ratings given by S\&P between two countries. A larger disparity in the credit quality of two countries is likely to reduce information transmission and hence, volatility linkages on the basis of risk-return arguments. Variable trades $s_{e q}$ is the difference in the average number of trades in the equity market between two countries scaled by the standard deviation of the total number of trades. Variable $\operatorname{trades}_{f x}$ is similarly defined for the foreign exchange market. These measures capture the relative difference in trading activity and development in terms of market depth and liquidity. A larger disparity in these aspects of financial market development is likely to reduce financial linkages. The 
pairwise correlations shown in Table 2 for variables used in these regressions suggest that multicollinearity is not a big problem in our chosen set of regressors.

Table 3 reports the estimated results. The nine controlled variables include economic, financial, and political risk indexes, equity and foreign exchange trading volumes, credit rating, gdp per capita, and dummy variables for foreign exchange regime, and region. The control variables are mostly significant in the expected direction. When the dependent variable is the correlation of realized volatilities (or alternatively, GARCH volatility), the estimate of the coefficient for culture distance is $-0.0296(-0.0196)$ with the t-statistic of -6.8755 (-6.0519), indicating that culturally similar countries have a lower degree of return volatility linkage. Conversely, two countries that share a close culture in terms of all six Hofstede dimensions will have a stronger volatility linkage.

\section{Channels through which culture affects volatility link- age among countries}

Evidence presented in our previous sections show that cultural distance is negatively related to volatility linkage. In this section we explore two possible channels through which culture might affect volatility linkages among countries. Specifically, we investigate whether bilateral investment and relative currency trading activity affect the relationship between culture distance and volatility linkage as correlated trading activity and openness have both recently been identified as important mechanisms for stock price synchronicity by Eun et al. (2015).

\section{A. Bilateral Investment and the culture-volatility relationship}

We conjecture that culture can influence the intensity of volatility linkages through a common investor base. Prior literature shows that investors tend to invest in countries that 
would be familiar to them and culturally similar to their home market. For instance, both Beugelsdijk and Frijns (2010) and Choi et al. (2014) document that investors tend to invest disproportionately in foreign markets that are more culturally proximate to their home countries and that these investors outperform those from culturally and geographically distant markets due to their information advantage. For this reason, we expect that cultural similarities work to induce a common investor base as they are more familiar to investors consistent with Huberman (2001)'s familiarity bias. Hence, we expect that there is a common investor base through which culture influences the intensity of volatility linkages. Hence, we run the following regression to account for this possibility using the amount of bilateral investments between country pairs and include the same set of control variables as above:

$$
\begin{aligned}
\text { VolatilityLinkage }_{i j}=\text { const }+\alpha_{1} C D_{i j}^{g e n} & +\alpha_{2} \text { investment }_{i j}+\alpha_{3} \text { CD }_{i j}^{\text {gen }} * \text { investment }_{i j} \\
& +\sum_{k=1}^{7} \gamma_{k} \text { ControlledVariable }_{i j, k}+e_{i j}
\end{aligned}
$$

The results are shown in Table 4. Model specification (1) is for Realized volatility linkages and (2) is for GARCH CCCs. We find that consistent with our expectations, for both measures of volatility linkages investments is significantly and positively related to volatility linkages and the interaction term between cultural distance and investments is negative indicating that when there is a larger common investor base between two countries, cultural proximity becomes even more important in strengthening volatility linkages.

\section{B. Relative trading volume and the culture-volatility relationship}

We now turn our attention to the role that relative currency trading volume plays in the culture-volatility relationship by running the following two regressions and include the same set of control variables as above: 


$$
\begin{aligned}
\text { VolatilityLinkage }_{i j}=\text { const }+\alpha_{1} C D_{i j}^{g e n} & +\alpha_{2} \text { trade }_{i j}^{e q}+\alpha_{3} C D_{i j}^{g e n} * \text { trade }_{i j}^{e q} \\
& +\sum_{k=1}^{7} \gamma_{k} \text { ControlledVariable }_{i j, k}+e_{i j}
\end{aligned}
$$

and

$$
\begin{aligned}
\text { VolatilityLinkage }_{i j}=\text { const }+\alpha_{1} C D_{i j}^{g e n} & +\alpha_{4} \text { trade }_{i j}^{f x}+\alpha_{5} C D_{i j}^{g e n} * \text { trade }_{i j}^{f x} \\
& +\sum_{k=1}^{7} \gamma_{k} \text { ControlledVariable }_{i j, k}+e_{i j}
\end{aligned}
$$

We measure relative openness and correlated equity trading based on the difference in foreign exchange $\left(\operatorname{trade}_{f x}\right)$ and equity trading volumes $\left(\operatorname{trade}_{e q}\right)$, respectively. The results are presented in Table 5. Model specifications (1) and (2) are for realized volatility linkages and (3) to (4) are for GARCH volatility linkages. For both volatility linkage measures we find that when one country is relatively less open than another country, the cultural distance between them exerts an even stronger negative effect on volatility linkages across the two countries equity markets. This corroborates with Eun et al. (2015)'s finding that trade and capital market openness weakens the effect of national culture on stock return co-movements. Domestic culture plays less of a role in investors trading decisions when markets are more economically and financially open and exposed to other foreign cultural influences. Furthermore, when there is less correlated trading across two equity markets, culture distance exerts a negative albeit insignificant effect on volatility linkages. This result also corroborates with Eun et al. (2015)'s finding that culture stimulates more correlated trading in equity markets. 


\section{Conclusions}

In this study we investigate whether cultural proximity can intensify volatility linkages across international equity markets. Using daily data on national stock market indices for a sample of 49 developed and developing countries over the period from 2000 to 2010, we find that our cultural distance measure is inversely related to the strength in return volatility linkages between country pairs suggesting that cultural similarities in market participants backgrounds are likely to induce systematic biases in investors reactions to information in financial trading decision. With regards to the mechanisms through which culture might influence volatility linkages, we also find evidence that national culture is particularly important when there is a wider common investor base between two markets with greater bilateral portfolio investments. Furthermore, we reveal that when one market within a country pair is relatively less open than another market in terms of their foreign exchange trading activity then the cultural distance between them will further weaken volatility linkages. Our results suggest that market participants with similar cultural backgrounds respond to and impound information into equity prices in a similar fashion and this works to intensify volatility linkages around the world.

It would be fruitful for further research in this area to explore the implications of cultural

links and systematic investor biases on the real economy such as the effects on aggregate investments and output. We leave this avenue for future research on culture and finance. 
Table I: List of countries and their Hofstede's six cultural dimensions. The cultural dimension data are readily available at http://www.geerthofstede.nl/research-vsm.aspx

\begin{tabular}{|c|c|c|c|c|c|c|c|c|}
\hline & & $\overline{p \text { pdi }}$ & $\overline{\text { idv }}$ & $\overline{\text { mas }}$ & uai & lto & $\overline{\text { ivr }}$ & $\overline{~ g d p p a ~}$ \\
\hline 1 & Vietnam & 70 & 20 & 40 & 30 & 57 & 35 & 540 \\
\hline 2 & India & 77 & 48 & 56 & 40 & 51 & 26 & 634 \\
\hline 3 & Philippines & 94 & 32 & 64 & 44 & 27 & 42 & 1235 \\
\hline 4 & Indonesia & 78 & 14 & 46 & 48 & 62 & 38 & 1285 \\
\hline 5 & Colombia & 67 & 13 & 64 & 80 & 13 & 83 & 1591 \\
\hline 6 & Morocco & 70 & 46 & 53 & 68 & 14 & 25 & 1692 \\
\hline 7 & Thailand & 64 & 20 & 34 & 64 & 32 & 45 & 2677 \\
\hline 8 & Peru & 64 & 16 & 42 & 87 & 25 & 46 & 2742 \\
\hline 9 & Canada & 39 & 80 & 52 & 48 & 36 & 68 & 2990 \\
\hline 10 & Croatia & 73 & 33 & 40 & 80 & 58 & 33 & 3113 \\
\hline 11 & Argentina & 49 & 46 & 56 & 86 & 20 & 62 & 3181 \\
\hline 12 & Romania & 90 & 30 & 42 & 90 & 52 & 20 & 3512 \\
\hline 13 & Russia & 93 & 39 & 36 & 95 & 81 & 20 & 4796 \\
\hline 14 & Malaysia & 104 & 26 & 50 & 36 & 41 & 57 & 4994 \\
\hline 15 & Bulgaria & 70 & 30 & 40 & 85 & 69 & 16 & 5138 \\
\hline 16 & Turkey & 66 & 37 & 45 & 85 & 46 & 49 & 5264 \\
\hline 17 & Venezuela & 81 & 12 & 73 & 76 & 16 & 100 & 5471 \\
\hline 18 & Poland & 68 & 60 & 64 & 93 & 38 & 29 & 6273 \\
\hline 19 & China & 80 & 20 & 66 & 30 & 87 & 24 & 6462 \\
\hline 20 & Australia & 36 & 90 & 61 & 51 & 21 & 71 & 6750 \\
\hline 21 & Hungary & 46 & 80 & 88 & 82 & 58 & 31 & 7543 \\
\hline 22 & Czech Rep & 57 & 58 & 57 & 74 & 70 & 29 & 9668 \\
\hline 23 & Malta & 56 & 59 & 47 & 96 & 47 & 66 & 12574 \\
\hline 24 & Korea South & 60 & 18 & 39 & 85 & 100 & 29 & 13222 \\
\hline 25 & Taiwan & 58 & 17 & 45 & 69 & 93 & 49 & 14022 \\
\hline 26 & Slovenia & 71 & 27 & 19 & 88 & 49 & 48 & 14130 \\
\hline 27 & Portugal & 63 & 27 & 31 & 104 & 28 & 33 & 14716 \\
\hline 28 & Greece & 60 & 35 & 57 & 112 & 45 & 50 & 16810 \\
\hline 29 & New Zealand & 22 & 79 & 58 & 49 & 33 & 75 & 20397 \\
\hline 30 & Spain & 57 & 51 & 42 & 86 & 48 & 44 & 20539 \\
\hline 31 & Hong Kong & 68 & 25 & 57 & 29 & 61 & 17 & 25267 \\
\hline 32 & Italy & 50 & 76 & 70 & 75 & 61 & 30 & 25663 \\
\hline 33 & Singapore & 74 & 20 & 48 & 8 & 72 & 46 & 26054 \\
\hline 34 & Austria & 11 & 55 & 79 & 70 & 60 & 63 & 28538 \\
\hline 35 & Great Britain & 35 & 89 & 66 & 35 & 51 & 69 & 28582 \\
\hline 36 & Chile & 63 & 23 & 28 & 86 & 31 & 68 & 28766 \\
\hline 37 & France & 68 & 71 & 43 & 86 & 63 & 48 & 29095 \\
\hline 38 & Germany & 35 & 67 & 66 & 65 & 83 & 40 & 30485 \\
\hline 39 & Brazil & 69 & 38 & 49 & 76 & 44 & 59 & 30565 \\
\hline 40 & Finland & 33 & 63 & 26 & 59 & 38 & 57 & 31362 \\
\hline 41 & Belgium & 65 & 75 & 54 & 94 & 82 & 57 & 32200 \\
\hline 42 & Netherlands & 38 & 80 & 14 & 53 & 67 & 68 & 32261 \\
\hline 43 & Ireland & 28 & 70 & 68 & 35 & 24 & 65 & 32620 \\
\hline 44 & Sweden & 31 & 71 & 5 & 29 & 53 & 78 & 35416 \\
\hline 45 & Japan & 54 & 46 & 95 & 92 & 88 & 42 & 35496 \\
\hline 46 & Denmark & 18 & 74 & 16 & 23 & 35 & 70 & 39694 \\
\hline 47 & Switzerland & 34 & 68 & 70 & 58 & 74 & 66 & 47867 \\
\hline 48 & Norway & 31 & 69 & 8 & 50 & 35 & 55 & 50927 \\
\hline 49 & Luxembourg & 40 & 60 & 50 & 70 & 64 & 56 & 64569 \\
\hline
\end{tabular}


Table II: Pairwise Correlations between all variables used.

\begin{tabular}{lrrrrrrrrrr}
\hline \hline & gdppa & econrisk & finarisk & polirisk & fxregm & rating & region & trades_eq & trades_fx & invment \\
CD_gen & $\mathbf{- 0 . 0 4 9}$ & $\mathbf{0 . 1 0 9}$ & $\mathbf{0 . 1 5 7}$ & $\mathbf{0 . 1 0 3}$ & -0.005 & 0.021 & $\mathbf{- 0 . 1 9 9}$ & $\mathbf{0 . 0 7 4}$ & 0.004 & $\mathbf{- 0 . 0 5 3}$ \\
gdppa & & $\mathbf{0 . 2 0 5}$ & 0.017 & $\mathbf{0 . 4 4 7}$ & $\mathbf{- 0 . 1 8 0}$ & $\mathbf{0 . 5 2 2}$ & $\mathbf{- 0 . 1 8 9}$ & $\mathbf{0 . 0 6 6}$ & $\mathbf{- 0 . 0 5 0}$ & $\mathbf{- 0 . 2 1 4}$ \\
econrisk & & & $\mathbf{0 . 6 3 4}$ & $\mathbf{0 . 4 9 1}$ & -0.022 & $\mathbf{0 . 3 5 5}$ & -0.036 & 0.016 & $\mathbf{0 . 0 9 3}$ & $\mathbf{- 0 . 1 3 9}$ \\
finarisk & & & $\mathbf{0 . 2 0 4}$ & 0.015 & $\mathbf{0 . 1 8 5}$ & $\mathbf{- 0 . 0 9 9}$ & -0.006 & -0.025 & $\mathbf{- 0 . 1 1 3}$ \\
polirisk & & & & $\mathbf{- 0 . 1 1 2}$ & $\mathbf{0 . 6 6 7}$ & $\mathbf{- 0 . 2 6 8}$ & 0.017 & 0.027 & $\mathbf{- 0 . 1 7 8}$ \\
fxregm & & & & & $\mathbf{- 0 . 1 4 1}$ & $\mathbf{0 . 1 1 7}$ & -0.003 & $\mathbf{- 0 . 0 5 1}$ & $\mathbf{0 . 2 1 9}$ \\
rating & & & & & & $\mathbf{- 0 . 2 1 7}$ & $\mathbf{0 . 0 5 6}$ & 0.032 & $\mathbf{- 0 . 2 5 3}$ \\
region & & & & & & & $\mathbf{0 . 0 7 3}$ & $\mathbf{- 0 . 1 0 4}$ & $\mathbf{0 . 2 0 7}$ \\
trades_eq & & & & & & & & & 0.003 & $\mathbf{0 . 1 1 0}$ \\
trades_fx & & & & & & & & & $\mathbf{0 . 0 6 7}$ \\
\hline \hline
\end{tabular}

Table III: This table shows the impact of bilateral investment on the relationship between our cultural distance measure and volatility linkages. Model specification (1) has realized volatility linkages as the dependent variable whilst (2) has GARCH volatility linkages as the dependent variable. We compute the adjusted heteroskedastic-serial t-statistics using the Newey-West procedure.

\begin{tabular}{lrrrr}
\hline \hline & Realized Volatility & \multicolumn{2}{c}{ GARCH Volatility } \\
& $(1)$ & Tstat & $(2)$ & Tstat \\
\hline & & & & \\
const & 0.6650 & 22.878 & 0.3412 & 14.410 \\
$C D^{g e n}$ & -0.0296 & -6.8755 & -0.0196 & -6.0519 \\
gdppa & -0.0105 & -1.4274 & -0.0317 & -4.7529 \\
econrisk & 0.0858 & 1.5335 & -0.0130 & -0.2479 \\
finarisk & 0.2799 & 4.3164 & 0.0722 & 1.1259 \\
polirisk & -0.0357 & -0.7487 & 0.0826 & 1.8383 \\
fxregm & 0.0312 & 2.3061 & 0.0383 & 3.0304 \\
rating & -0.1427 & -6.4963 & -0.0802 & -3.5978 \\
region & 0.0491 & 4.3029 & 0.1166 & 9.1451 \\
trades_eq & -0.0210 & -2.2950 & -0.0151 & -1.5820 \\
trades_fx & -0.0127 & -1.9519 & 0.0025 & 0.5291 \\
& & & & \\
Adj $R^{2}$ & 0.1863 & & 0.2295 & \\
Nobs & 1176 & & 1176 & \\
\hline \hline
\end{tabular}


Table IV: This table shows the impact of bilateral investment on the relationship between our cultural distance measure and volatility linkages. Model specification (1) has realized volatility linkages as the dependent variable whilst (2) has GARCH volatility linkages as the dependent variable. We compute the adjusted heteroskedastic-serial t-statistics using the Newey-West procedure.

\begin{tabular}{lrrrr}
\hline & \multicolumn{2}{r}{ Realized Volatility } & \multicolumn{2}{c}{ GARCH Volatility } \\
\hline & & & & \\
& $(1)$ & Tstat & $(2)$ & Tstat \\
const & 0.6257 & 23.442 & 0.3170 & 14.563 \\
CD_gen & -0.0295 & -6.5444 & -0.0188 & -5.8206 \\
investment & 1.0874 & 0.8528 & 1.5695 & 1.3830 \\
CD_gen*investment & -0.2073 & -0.7480 & -0.2351 & -0.9817 \\
gdppa & -0.0093 & -1.2828 & -0.0302 & -4.6232 \\
econrisk & 0.0598 & 1.0760 & -0.0006 & -0.0118 \\
finarisk & 0.3108 & 4.9180 & 0.0842 & 1.3489 \\
polirisk & -0.0273 & -0.5616 & 0.0707 & 1.5781 \\
fxregm & 0.0317 & 2.2083 & 0.0300 & 2.2757 \\
rating & -0.1471 & -6.5454 & -0.0715 & -3.2136 \\
region & 0.0478 & 4.1851 & 0.1070 & 8.4792 \\
& & & & \\
Adj $R^{2}$ & 0.1754 & & 0.2377 & \\
Nobs & 1176 & & 1176 & \\
\hline \hline
\end{tabular}


Table V: This table shows that the relationship between cultural distance and volatility linkage is dependent on relative trading volume in equity and currency markets. Model specifications (1)-(2) have realized volatility linkages as the dependent variable whilst (3)-(4) have GARCH volatility linkages as the dependent variable. We compute the adjusted heteroskedastic-serial t-statistics using the Newey-West procedure.

\begin{tabular}{lrrrrrrrr}
\hline \hline & \multicolumn{3}{c}{ Realized Volatility } & \multicolumn{3}{c}{ GARCH Volatility } \\
& $(1)$ & Tstat & $(2)$ & Tstat & $(3)$ & Tstat & $(4)$ & Tstat \\
\hline & & & & & & & & \\
const & 0.616 & 17.91 & 0.582 & 17.63 & 0.379 & 11.48 & 0.285 & 9.556 \\
CD_gen & -0.023 & -3.642 & -0.017 & -3.043 & -0.026 & -4.868 & -0.012 & -2.387 \\
trades_eq & 0.005 & 0.248 & & & -0.045 & -1.765 & & \\
CD_gen*trades_eq & -0.005 & -1.203 & & & 0.006 & 1.404 & & \\
trades_fx & & & 0.049 & 2.597 & & & 0.043 & 2.739 \\
CD_gen*trades_fx & & & -0.012 & -3.469 & & & -0.008 & -2.881 \\
gdppa & -0.009 & -1.235 & -0.013 & -1.730 & -0.032 & -4.733 & -0.033 & -5.028 \\
econrisk & 0.062 & 1.149 & 0.082 & 1.474 & -0.009 & -0.182 & -0.016 & -0.297 \\
finarisk & 0.294 & 4.628 & 0.276 & 4.288 & 0.077 & 1.203 & 0.070 & 1.080 \\
polirisk & -0.032 & -0.666 & -0.033 & -0.682 & 0.085 & 1.891 & 0.085 & 1.863 \\
fxregm & 0.032 & 2.331 & 0.031 & 2.297 & 0.039 & 3.053 & 0.038 & 3.049 \\
rating & -0.142 & -6.363 & -0.142 & -6.308 & -0.083 & -3.696 & -0.080 & -3.509 \\
region & 0.052 & 4.659 & 0.044 & 3.806 & 0.117 & 9.334 & 0.113 & 8.688 \\
& & & & & & & & \\
Adj $R^{2}$ & 0.184 & & 0.183 & & 0.231 & & 0.227 & \\
Nobs & 1176 & & 1176 & & 1176 & & 1176 & \\
\hline \hline
\end{tabular}




\section{Appendix}

Table VI: List of variables used and their description and data source

gdppa is real GDP per capital.

Source: World Bank Development Indicators

Variables econrisk, finarisk, and polirisk are the difference of average economic, financial, and political risk indexes between two countries, respectively.

Source: International Country Risk Guide (ICRG)

fxregm is a dummy variable equal to 1 if the two countries share the same forex regime, and zero otherwise.

Source: International Moneytary Fund

rating is the difference of the average credit rating between two countries.

Source: Standard \& Poor's

region is a dummy variable equal to 1 if the two countries are in the

same region, and zero otherwise.

Source: World Bank Development Indicators

trades_eq is the difference of the average number of trades in the equity market between two countries scaled by the standard deviation of all number of trades.

trades_f $x$ the difference of the average number of trades in the foreign exchange market between two countries scaled by the standard deviation of all number of trades.

investment is the bilateral portfolio equity investment computed as the sum of portfolio equity investment between two countries denominated in USD.

Source: Coordinated Portfolio Investment Survey, IMF 


\section{References}

Aggarwal, R. and Goodell, J. W. (2010), 'Financial markets versus institutions in european countries: Influence of culture and other national characteristics', International Business Review 19(5), 502-520.

Akhtar, S., Jahromi, M., John, K. and Moise, C. (2011), Intensity of volatility linkages between islamic and conventional markets, in 'AFA 2012 Chicago Meetings Paper'.

Amadi, A. A. (2004), 'Does familiarity breed investment? an empirical analysis of foreign equity holdings', Working paper, University of California.

Andersen, T. G., Bollerslev, T., Diebold, F. X. and Ebens, H. (2001), 'The distribution of realized stock return volatility', Journal of Financial Economics 61(1), 43-76.

Anderson, C. W., Fedenia, M., Hirschey, M. and Skiba, H. (2011), 'Cultural influences on home bias and international diversification by institutional investors', Journal of Banking 83 Finance 35(4), 916-934.

Bae, S. C., Chang, K. and Kang, E. (2012), 'Culture, corporate governance, and dividend policy: international evidence', Journal of Financial Research 35(2), 289-316.

Bauwens, L., Laurent, S. and Rombouts, J. V. (2006), 'Multivariate garch models: a survey', Journal of applied econometrics 21(1), 79-109.

Bekaert, G., Harvey, C. R., Lundblad, C. T. and Siegel, S. (2011), 'What segments equity markets?', Review of Financial Studies 24(12), 3841-3890.

Beugelsdijk, S. and Frijns, B. (2010), 'A cultural explanation of the foreign bias in international asset allocation', Journal of Banking \& Finance 34(9), 2121-2131.

Bollerslev, T. (1986), 'Generalized autoregressive conditional heteroskedasticity', Journal of econometrics 31(3), 307-327.

Chan, A. W. and Cheung, H. Y. (2012), 'Cultural dimensions, ethical sensitivity, and corporate governance', Journal of business ethics 110(1), 45-59.

Chan, K., Covrig, V. and Ng, L. (2005), 'What determines the domestic bias and foreign bias? evidence from mutual fund equity allocations worldwide', The Journal of Finance 60(3), 1495-1534.

Choi, N., Fedenia, M., Skiba, H. and Sokolyk, T. (2014), 'Portfolio concentration and performance of institutional investors worldwide', working paper. 
Chui, A. C., Titman, S. and Wei, K. J. (2010), 'Individualism and momentum around the world', The Journal of Finance 65(1), 361-392.

Cifarelli, G. and Paladino, G. (2008), 'Reserve overstocking in a highly integrated world. new evidence from asia and latin america', The European Journal of Finance 14(4), 315-336.

Colla, P. and Mele, A. (2010), 'Information linkages and correlated trading', Review of Financial Studies 23(1), 203-246.

Drogendijk, R. and Slangen, A. (2006), 'Hofstede, schwartz, or managerial perceptions? the effects of different cultural distance measures on establishment mode choices by multinational enterprises', International business review 15(4), 361-380.

Eckel, S., Löffler, G., Maurer, A. and Schmidt, V. (2011), 'Measuring the effects of geographical distance on stock market correlation', Journal of Empirical Finance 18(2), 237-247.

Engle, R. F. (1982), 'Autoregressive conditional heteroscedasticity with estimates of the variance of united kingdom inflation', Econometrica: Journal of the Econometric Society pp. $987-1007$.

Eun, C. S., Wang, L. and Xiao, S. C. (2012), 'Culture and stock price synchronicity: The effects of tightness and individualism', Available at SSRN 2021614.

Eun, C. S., Wang, L. and Xiao, S. C. (2015), 'Culture and r 2', Journal of Financial Economics 115(2), 283-303.

Fleischer, P. (2003), 'Volatility and information linkages across markets and countries', Australian Journal of Management 28(3), 251-272.

Fleischer, P., Maller, R. and Müller, G. (2011), 'A bayesian analysis of market information linkages among nafta countries using a multivariate stochastic volatility model', Journal of Economics and Finance 35(2), 123-148.

Fleming, J., Kirby, C. and Ostdiek, B. (1998), 'Information and volatility linkages in the stock, bond, and money markets', Journal of financial economics 49(1), 111-137.

French, K. R. and Poterba, J. M. (1991), Investor diversification and international equity markets, Technical report, National Bureau of Economic Research.

Giannopoulos, K., Nekhili, R. and Koutmos, G. (2010), 'Volatility spillovers and price interdependencies; a dynamic non parametric approach', International Research Journal of Finance and Economics p. 115.

Grinblatt, M. and Keloharju, M. (2001), 'How distance, language, and culture influence stockholdings and trades', The Journal of Finance 56(3), 1053-1073. 
Han, S., Kang, T., Salter, S. and Yoo, Y. K. (2010), 'A cross-country study on the effects of national culture on earnings management', Journal of International Business Studies 41(1), 123-141.

Harvey, C. R. and Huang, R. D. (1991), 'Volatility in the foreign currency futures market', Review of Financial Studies 4(3), 543-569.

Hofstede, G. (2011), 'Dimensionalizing cultures: The hofstede model in context', Online readings in psychology and culture $\mathbf{2}(1), 8$.

Huberman, G. (2001), 'Familiarity breeds investment', Review of financial Studies 14(3), 659-680.

Jiang, G. J., Konstantinidi, E. and Skiadopoulos, G. (2012), 'Volatility spillovers and the effect of news announcements', Journal of Banking $\&$ Finance 36(8), 2260-2273.

Kim, S. J., Moshirian, F. and Wu, E. (2005), 'Dynamic stock market integration driven by the european monetary union: An empirical analysis', Journal of Banking \& Finance 29(10), 2475-2502.

Kogut, B. and Singh, H. (1988), 'The effect of national culture on the choice of entry mode', Journal of international business studies pp. 411-432.

Koopman, S. J., Jungbacker, B. and Hol, E. (2005), 'Forecasting daily variability of the s\&p 100 stock index using historical, realised and implied volatility measurements', Journal of Empirical Finance 12(3), 445-475.

Korkmaz, T., Çevik, E. İ. and Atukeren, E. (2012), 'Return and volatility spillovers among civets stock markets', Emerging Markets Review 13(2), 230-252.

Kwok, C. C. and Tadesse, S. (2006), 'National culture and financial systems', Journal of International Business Studies 37(2), 227-247.

Laopodis, N. T. (2002), 'Volatility linkages among interest rates: Implications for global monetary policy', International Journal of Finance $\&$ Economics 7(3), 215-233.

Lee, S.-H., Shenkar, O. and Li, J. (2008), 'Cultural distance, investment flow, and control in cross-border cooperation', Strategic Management Journal 29(10), 1117-1125.

Li, K., Griffin, D., Yue, H. and Zhao, L. (2011), 'National culture and capital structure decisions: Evidence from foreign joint ventures in china', Journal of International Business Studies 42(4), 477-503.

Lucey, B. M. and Zhang, Q. (2010), 'Does cultural distance matter in international stock market comovement? evidence from emerging economies around the world', Emerging 
Markets Review 11(1), 62-78.

Martens, M. and Zein, J. (2004), 'Predicting financial volatility: High-frequency time-series forecasts vis-à-vis implied volatility', Journal of Futures Markets 24(11), 1005-1028.

Morana, C. and Beltratti, A. (2008), 'Comovements in international stock markets', Journal of International Financial Markets, Institutions and Money 18(1), 31-45.

Parker, T. and Parker, M. (2014), 'Asian stock market empirical comovement: a sign of efficiency or multi-country financial crisis', Business Quest.

Roe, M. J. (2003), 'Political determinants of corporate governance: Political context, corporate impact', Harvard Law School John M. Olin Center for Law, Economics and Business Discussion Paper Series.

Sabri, N. R. (2002), 'Increasing linkages of stock markets and price volatility', Research in International Business and Finance 16, 349-374.

Sakthivel, P., Bodkhe, N. and Kamaiah, B. (2012), 'Correlation and volatility transmission across international stock markets: A bivariate garch analysis', International Journal of Economics and Finance 4(3), p253.

Stulz, R. M. and Williamson, R. (2003), 'Culture, openness, and finance', Journal of financial Economics 70(3), 313-349.

Walti, S. (2005), 'The macroeconomic determinants of stock market synchronization', Journal of International Banking Law 11(10), 436-41.

Wang, K. (2009), 'Volatility linkages of the equity, bond and money markets: an implied volatility approach', Accounting \& Finance 49(1), 207-219.

Wongswan, J. (2006), 'Transmission of information across international equity markets', Review of Financial Studies 19(4), 1157-1189.

Yeganeh, H. (2011), 'A generic conceptualization of the cultural distance index: Application to schwartz's and hofstede's frameworks', Journal of Strategy and Management 4(4), 325346. 